International Journal of Current Advanced Research

ISSN: O: 2319-6475, ISSN: P: 2319 - 6505, Impact Factor: SJIF: 5.995

Available Online at www.journalijcar.org

Volume 6; Issue 5; May 2017; Page No. 3641-3644

DOI: http://dx.doi.org/10.24327/ijcar.2017.3644.0337

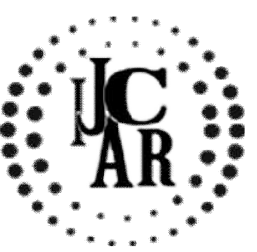

Case Report

\title{
MANAGEMENT OF CLASS III MALOCCLUSION IN CHILDREN
}

\section{Valli B}

Saveetha University

\begin{tabular}{|c|c|}
\hline A $R$ R T I C L E $\quad$ I N F O & A B S T R A C T \\
\hline Article History: & \multirow{7}{*}{$\begin{array}{l}\text { The aim of this article is to review the various types of management of class III } \\
\text { malocclusion in children. Class III malocclusion is one of the very severe dentofacial } \\
\text { anomalies. This malocclusion is classified into dentoalveolar, skeletal or functional, that } \\
\text { determines the prognosis. The facial growth of Class III malocclusion worsens with age. } \\
\text { Class III malocclusion poses a challenging dilemma for the clinician because these children } \\
\text { have of growth patterns that differ from that of children with class I malocclusion. The } \\
\text { mandible grows more rapidly than the maxilla, exacerbating the class III malocclusion as } \\
\text { the child go through adolescence. A review on Management of Class III malocclusion in } \\
\text { children will help us to know more about it and also to find few more options to manage } \\
\text { the class III malocclusion. }\end{array}$} \\
\hline Received $15^{\text {th }}$ February, 2017 & \\
\hline Received in revised form $9^{\text {th }}$ March, 2017 & \\
\hline Accepted $10^{\text {th }}$ April, 2017 & \\
\hline Published online $28^{\text {th }}$ May, 2017 & \\
\hline Key words: & \\
\hline $\begin{array}{l}\text { Children, malocclusion, maxillofacial } \\
\text { growth, prognathism }\end{array}$ & \\
\hline
\end{tabular}

Copyright $(2017$ Valli B. This is an open access article distributed under the Creative Commons Attribution License, which permits unrestricted use, distribution, and reproduction in any medium, provided the original work is properly cited.

\section{INTRODUCTION}

The treatment of Class III malocclusion is one of the biggest problems for orthodontist, due to mandibular growth. Previously, most of the Class III malocclusions were attributed completely to the large or prognathic mandible. But recently, we know that it can be caused due to maxillary retrognathism, mandibular prognathism, or a combination of both. Ideally, diagnosis of this malocclusion should be made as early as possible, still during deciduous dentition. Class III Malocclusion, when not treated at the initial stage of development, might interfere with normal growth of the jaws and may result in severe facial deformities. Therefore treatment should be carried out as early as possible for permitting normal growth of the skeletal bases. The early orthopaedic management of Class III malocclusions, at the final stage of primary dentition or the early stage of mixed dentition, prior to growth spurt, provides more of successful results, providing facial balance, altering the maxillofacial growth and development, also preventing a future surgical treatment by increasing the stability. The treatment option for class III malocclusion is based on the severity of malocclusion and the growth status of the patient.

\section{Aetiology of Class III Malocclusion}

In terms of etiology, malocclusion can have either a genetic $\operatorname{origin}^{[1]}$, with a more unfavourable prognosis ${ }^{[2]}$, or an environmental origin caused by moreanterior and inferior tongue positioning ${ }^{[3]}$, habits, and oral breathing ${ }^{[4]}$.Skeletal class III malocclusions are mostlypresent with maxillary

*Corresponding author: Valli B

Saveetha University retrognathia, mandibular prognathia, or a combination of both, of which maxillary retrognathia is seenin majority of these patients ${ }^{[5]}$. Pseudo class III malocclusion is a habitual malocclusion established bycross-bite of all anterior teeth, without the presence of any skeletal discrepancy, resulting from functional forward positioning/shift of the mandible on closure.

Therefore the possible aetiology for Class III malocclusion can be

- Class III has strong hereditary components

- Anteriorly positioned tongue

- Abnormal incisal guidance (pseudo class III).

Indication and Contraindications for Early Management Of Class III Malocclusion

Turpin created a list of positive and negative factors to help in deciding when to correct a developing Class III malocclusion $^{[6]}$. The positive factors are the following

- Good facial aesthetics

- Mild skeletal disharmony

- No familial prognathism

- Presence of anteroposterior functional shift

- Convergent facial type

- Symmetric condylar growth

- Growing patients with expected good cooperation.

The negative factors are as following

- Poor facial aesthetics

- Severe skeletal disharmony

- Familial pattern established 
- No anteroposterior shift

- Divergent facial type

- Asymmetric condylar growth

- Growth complete

- Poor cooperation.

Turpin also recommended that early treatment should be indicated for a patient who presents with positive characteristics and for those who present with negative characteristics, treatment can be delayed until growth is completed $^{[6]}$.

\section{Methods of Management of Class Iii Malocclusion}

Many treatment approaches can be found in the literature regarding orthopaedic and orthodontic treatment in class III malocclusion, including intraoral and extra-oral appliances such as a facial mask $(\mathrm{FM})^{[7]}$, functional functional regulator3 appliance of Franke ${ }^{[8]}$, removable mandibular retractor ${ }^{[9]}$, chin-cup $^{[10]}$, splints, class III elastics and chin-cup ${ }^{[11]}$, and mandibular cervical headgear ${ }^{[3,12]}$.

\section{Advantages of early management of class III malocclusion}

The early Class III treatment has many advantages: it facilitates the eruption of canines and premolars in a normal relation, eliminates the traumatic occlusion of incisors, that might lead to gingival recession, also provides an adequate maxillary growth, andimproves the self esteem of the child.

\section{Treatment prognosis in each method of management}

\section{Case report 1}

Case report describing the early orthopedic treatment and stability of Class III malocclusion, achieved by Rapid maxillary expansion and Facemask therapy, 15 years post treatment followup.

A 7.6 year old boy presented witha main facial symptom, due to an asymmetric mandible, which was shifted to the right. The nasolabial angle was increased and the poor development of the zygomatic region indicated a maxillary deficiency ${ }^{[\text {[Fig-1] }}$

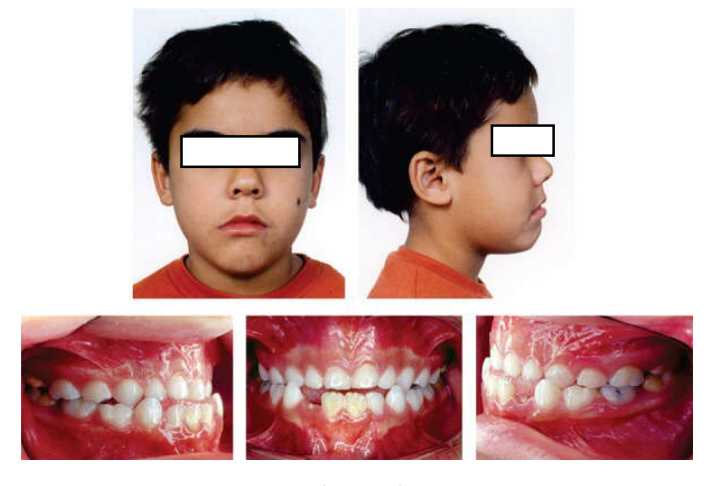

Figure-1

The intraoral exam indicated that the patient was in his mixed dentition stage with an anterior cross-bite, with no deviation of centric occlusion to the centric relation. The terminal plan of primary second molars exhibited a mesial-step, with the left side presented canines in a cross-bite relationship ${ }^{[\text {fig-1] }}$.

The panoramic radiograph showed no missing teeth and no pathologies. The cephalometric analysis demonstrated the maxilla to be lightly retracted and the mandible to be protruded. Thus, they presented a deficient relationship between them. Thus through the clinically obtained data the case was confirmed to be a class III malocclusion along with anterior cross-bite, due to slight maxillary retraction, mandibular protrusion and good skeletal pattern. The treatment chosen for this patient was rapid maxillary expansion and face-mask therapy. This treatment methodology restores facial aesthetics and dental relationship, by giving occlusion stability.

\section{Treatment prognosis discussions (1)}

The goals were established through orthopedic treatment of the Class III malocclusion associated with anterior cross-bite by using rapid maxillary expansion and the facial mask. This approach is mostlyadvised for patients in their mixed and primary dentitions ${ }^{[13,14,15]}$ and this approach also showed to be stable 15 years posttreatment. The effects of maxillary protraction in different ages (deciduous, mixed, and late mixed dentition) did not show much significant results ${ }^{[16]}$. Whereas, Baccetti, et al. 4 (1998) assessed two different age groups using maxillary expanders and facial masks ${ }^{[13]}$, and noticed a markedly greater advance of the maxillary structures in the younger age group of people. The increase might have occurred due to the rapid maxillary expansion, prior to the facial mask ${ }^{[17]}$. Besides correcting the posterior cross-bite, this expansion has also improved the partial disarticulation of the maxilla at its suture level, providing cellular activity stimulation in these areas, improving the orthopedic action of maxillary protraction forces. Also, this previous expansion prevented the anterior maxillary constriction, which might take place during maxillary protraction [15,18,19,20]. The intensity of the maxillary protraction force, as well the facial mask's daily use time, differs according to several researchers $[3,13,15,19,21,22,23,24]$, ranging from 500 to 2,000 grams. However, a lower intensity force in the beginning of the treatment, around 150 to 200 grams, which was gradually increased to 550 grams, helped the patient to adapt to the facial mask.

\section{Case Report-2}

A 9-year-old female patient in the mixed dentition stage (second transitional period) ${ }^{[25]}$ required treatment for anterior cross-bite. During the clinical checkup, the presence of class III malocclusion in other family members was identified. Facial evaluation indicated lack of development of the middle third, which is an apparently normal feature for Asians. Intraoral examination showed a forward shift of the mandible, with a marked mesial molar relationship, and a cross-bite of the four permanent incisors, thus indicating a functional Class III malocclusion ${ }^{[\text {fig-2]. }}$.
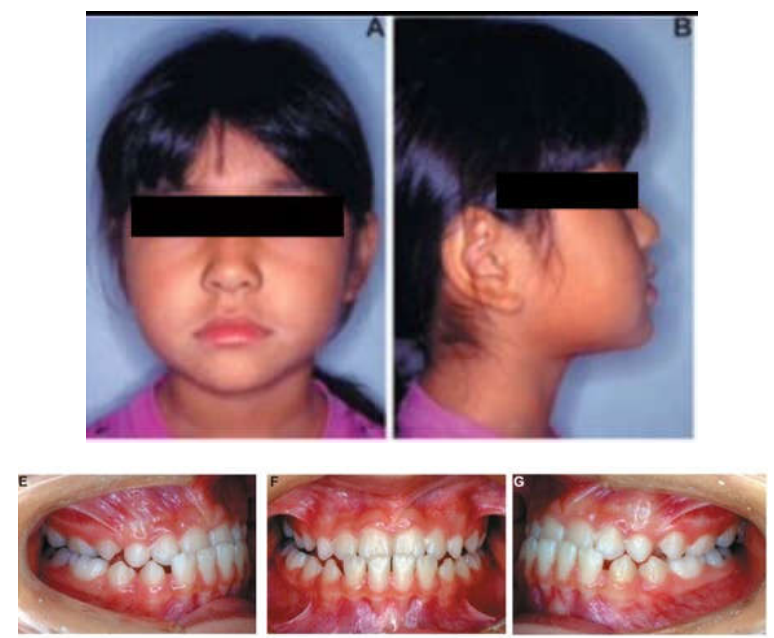

Figure-2 
The proposed treatment protocol comprised two stages: the interceptive and the corrective phases. In the first phase, a chin-cup was used only at night to maintain mandibular retrusion, and the Eschler appliance, also known as "progenic appliance", was used during the day. After correcting the cross-bite, the resin covering the occlusal surface was cut at each appointment. This was accomplished in order to allow the eruption of the premolars, eliminate the free space caused by the occlusal opening, and avoid a tongue interposition, and a possible posterior open bite.

Follow-up appointments were scheduled until the complete correction of the anterior cross-bite, totalizing a treatment period of 14 months. When the appliances were removed, the patient was seen every six months, up to the complete development of the permanent dentition, characterizing thus the end of the interceptive phase.

\section{Treatment prognosis and discussions (2)}

In this case, Class III was intercepted, and a fixed appliance was installed only to correct small rotations, the anterior diastema, and to improve axial teeth relationships. The changes in linear and angular measurements of the upper and lower incisors added to obtain a positive over-jet. From 9 to 12 years of age a proclination of the upper incisors from $20^{\circ}$ to $25^{\circ}$, and a retroclination of the lower incisors from $30^{\circ}$ to $22^{\circ}$ were observed. This occurred due to the positive effect of the anterior cross-bite correction.

Corrective orthodontic treatment was initiated 2 years after the finalization of the interceptive phase. On observing from the end of interceptive phase to the ten year followup of corrective phase there was a considerable amount of mandibular growth similar to normal mandibular growth, contributing for the maintenance of the positive over-jet. The linear and angular measurement changes of upper and lower incisors helped to obtain a positive over-jet. Sakamoto, et al. (1984), in a longitudinal study with skeletal Class III patients, radiographically evaluated the skeletal changes before, during and after chin-cup therapy.

This study demonstrated the success of optimal results, and the stability of the correction of a functional Class III malocclusion treated with a progenic appliance associated with a chin-cup, and followed by corrective orthodontics. Despite of the good outcomes achieved in this case, further long-term clinical investigations are necessary to assure the stability of Class III treatment.

\section{CONCLUSION}

The main aim of all treatment options in developing class III malocclusions, with or without positional malocclusions, is to improve the facial profile of the child and to allow the normal growth of the jaw bones. Children at the age of skeletal development should be given much importance for the management of class III malocclusion management and also regular followup should be maintained to prevent relapse.

\section{References}

1. Toffol LD, Pavoni C, Baccetti T, Franchi L, Cozza P. Orthopedic treatment outcomes in Class III malocclusion. A systematic review. Angle Orthod. 2008;78(3):561-73
2. Arun T, Nalbantgil D, Sayinsu K. Orthodontic treatment protocol of Ehlers-Danlos syndrome type VI. Angle Orthod. 2006; 76(1):177-83.

3. Cozzani G. Extraoral traction and class III treatment. Am J Orthod. 1981; 80(6):638-50.

4. Chung JC. Redirecting the growth pattern with rapid maxillary expander and chin cup treatment: changing breathing pattern from oral to nasal. World J Orthod. 2006; 7(3):236-53.

5. Guyer EC, Ellis EE 3 rd, McNamara JA Jr, Behrents RG. Components of class III malocclusion in juveniles and adolescents. Angle Orthod 1986; 56:7-30.

6. Turpin DL: Early Class III treatment. Unpublished thesis presented at $81 \mathrm{st}$ session of the American Association of Orthodontists, San Fran- cisco, 1981

7. Masucci C, Franchi L, Defraia E, Mucedero M, Cozza $\mathrm{P}$, Baccetti T. Stability of rapid maxillary expansion and facemask therapy: A long-term controlled study. Am J Orthod Dentofacial Orthop. 2011; 140:493-500. [PubMed].

8. Gianelly AA, Brosnan P, Martignoni M, Bernstein L. Mandibular growth, condyle position and Fränkel appliance therapy. Angle Orthod. 1983; 53:131-42. [PubMed]

9. Tollaro I, Baccetti T, Franchi L. Mandibular skeletal changes induced by early functional treatment of class III malocclusion: A superimposition study. Am J Orthod Dentofacial Orthop. 1995; 108:525-32. [PubMed]

10. Graber LW. Chin cup therapy for mandibular prognathism. Am J Orthod. 1977; 72:23-41. [PubMed]

11. Ferro A, Nucci LP, Ferro F, Gallo C. Long-term stability of skeletal class III patients treated with splints, class III elastics, and chincup. Am J Orthod Dentofacial Orthop. 2003; 123:423-34. [PubMed]

12. Rey D, Angel D, Oberti G, Baccetti T. Treatment and posttreatment effects of mandibular cervical headgear followed by fixed appliances in Class III malocclusion. Am J Orthod Dentofacial Orthop. 2008; 133:371-8. [PubMed]

13. Baccetti T, Tollaro I. A retrospective comparison of functional appliance treatment of Class III malocclusions in the deciduous and mixed dentitions. Eur J Orthod. 1998; 20(3):309-317. [PubMed]

14. McNamara JA., Jr An orthopedic approach to the treatment of Class III malocclusion in young patients. $J$ Clin Orthod. 1987;21(9):598-608. [PubMed]

15. Turley PK. Orthopedic correction of Class III malocclusion with palatal expansion and custom protraction headgear. J Clin Orthod. 1988; 22(5):314325. [PubMed]

16. Sung SJ, Baik HS. Assessment of skeletal and dental changes by maxillary protraction. Am J Orthod Dentofacial Orthop. 1998; 114(5):492-502. [PubMed]

17. Baccetti T, McGill JS, Franchi L, McNamara JA, Jr, Tollaro I. Skeletal effects of early treatment of Class III malocclusion with maxillary expansion and face-mask therapy. Am J Orthod Dentofacial Orthop. 1998; 113(3):333-343. [PubMed]

18. GekKiow G, Kaan SK. Dentofacial orthopaedic correction of maxillary retrusion with the protraction facemask - a literature review. Aust Orthod J. 1992; 12(3):143-150. [PubMed] 
19. Hata S, Itoh $\mathrm{T}$, Nakagawa $\mathrm{M}$, Kamogashira $\mathrm{K}$, Ichikawa $\mathrm{K}$, Matsumoto $\mathrm{M}$, et al. Biomechanical effects of maxillary protraction on the craniofacial complex. Am J Orthod Dentofacial Orthop. 1987; 91(4):305-311. [PubMed]

20. Itoh $\mathrm{T}$, Chaconas SJ, Caputo AA, Matyas J. Photoelastic effects of maxillary protraction on the craniofacial complex. Am J Orthod. 1985; 88(2):117124. [PubMed].

21. Hickham JH. Maxillary protraction therapy: diagnosis and treatment. J Clin Orthod. 1991; 25(2):102-113. [PubMed]
22. Irie M, Nakamura S. Orthopedic approach to severe skeletal Class III malocclusion. Am J Orthod. 1975; 67(4):377-392. [PubMed]

23. Nanda R. Biomechanical and clinical considerations of a modified protraction headgear. Am J Orthod. 1980; 78(2):125-139. [PubMed]

24. Wisth PJ, Tritrapunt A, Rygh P, Bøe OE, Norderval K. The effect of maxillaryprotraction on front occlusion and facial morphology. Acta Odontol Scand. 1987; 45(3):227-237. [PubMed]

25. Van Der Linden FPGM. Facial growth and facial orthopedics. 2nd ed. Chicago: Quintessence; 1986.

\section{How to cite this article:}

Valli B (2017) ' Management Of Class Iii Malocclusion In Children', International Journal of Current Advanced Research, 06(05), pp. 3641-3644.

DOI: http://dx.doi.org/10.24327/ijcar.2017.3644.0337 